\title{
Healthcare Providers' Knowledge and Their Perceived Factors Influencing Cancer Palliative Care Services in Kwazulu-natal
}

Minenhle Dlamini ( $\nabla$ minenhledl@gmail.com )

University of KwaZulu-Natal College of Health Sciences https://orcid.org/0000-0002-8056-5735

Khumbulani W. Hlongwana

University of KwaZulu-Natal College of Health Sciences

Themba G. Ginindza

University of KwaZulu-Natal College of Health Sciences

Research article

Keywords: Cancer, palliative care, community caregivers, healthcare providers

Posted Date: January 6th, 2020

DOl: https://doi.org/10.21203/rs.2.20135/v1

License: (c) (i) This work is licensed under a Creative Commons Attribution 4.0 International License.

Read Full License 


\section{Abstract}

Background: Healthcare providers spend most of their time in direct care of critically ill patients. The family members of the critically ill patients are not spared from managing physical, psychological, emotional and spiritual symptoms, yet many of them feel anxious and unprepared to care for palliative patients. The purpose of this study was to determine healthcare providers' knowledge and perceived factors influencing cancer palliative care (PC) services in the selected sites of Durban and Pietermaritzburg, KZN.

Methods: This was a mixed methods study using a structured questionnaire and focus group discussions (FGDs) for quantitative and qualitative aspects, respectively. All healthcare providers were selected through convenience sampling, based on being relevant to the study objectives. Twenty-seven healthcare providers participated in structured questionnaires with eight being further selected to participate in an FGD based on being information-rich. IBM SPSS Statistics (v.25) and NVIVO 12 Pro software were used to analyze quantitative and qualitative data, respectively.

Results: The mean ( \pm SD) age of the 27 participants was $42.52( \pm 11.37)$ years and about $48.1 \%$ were within the age-group 31-40 years. The majority of participants were females (77.7\%) and were married (59.5\%). More than four-fifths (81.5\%) had attended up to tertiary level as the highest level of education, $85.1 \%$ were permanently employed and $96.3 \%$ were from urban areas. The majority of participants had been trained in PC (70.4\%), 55.5\% had less than five years' experience working as palliative healthcare providers and $51.8 \%$ rated their experience of caring for cancer patients as good. Perceived barriers in patients seeking PC, included three themes, namely: (1) effects of intra-departmental collaboration, (2) caregivers' perspectives regarding the complexities of PC seeking barriers and (3) innate factors that sustain the community caregivers' motivation.

Conclusion: Healthcare providers trained and/or implementing PC have varying levels of competencies, suggesting a need for continuous professional development (CPD) to build PC skills. The results also provided clear evidence that collaboration among the stakeholders within the Department of Health can potentially enhance PC service delivery in KwaZulu-Natal.

\section{Background}

The increasing burden of life-threatening diseases in sub-Saharan Africa (SSA) is reflected in the epidemiology of HIV and cancer in the region (1). In 2007, SSA had 22.5 million people living with HIV infection and 1.6 million people died of AIDS-related conditions (2). On the other hand, cancer and other non-communicable diseases (NCDs) are compounding the disease burden, with the reports indicating that approximately one in five deaths in SSA is due to cancer $(3,4)$. By 2050 , the lifetime risk of cancer in SSA is expected to increase by $50-60 \%$, and the annual number of cases will rise from 650000 to 2.2 million (5). These projections call for a rethink of how PC services can be interactively packaged into the healthcare systems. 
PC is defined by the World Health Organization (WHO) as "an approach that improves the quality of life of patients and their families facing the problems associated with life-threatening illness, through prevention and relief of suffering by means of early identification and impeccable assessment and treatment of pain and other problems, physical, psychosocial and spiritual" (6). This definition illustrates that the goal of PC is to improve the quality of life of a terminally ill person while relieving their suffering and not necessarily curing them of their illness. In addition, PC is applicable in the early course of illness in conjunction with other forms of therapies like radiotherapy and chemotherapy that are intended to prolong life (7).

Therefore PC is an essential component of public health services in SSA; however, the current provision in the region is patchy, and the coverage is poor (8). Successful models of hospital and community-homebased PC services in the region have been described, but also significant challenges have been observed (9). These include a lack of access to essential drugs, poor social conditions (10), a lack of collaboration among the stakeholders from the Department of Health and a lack of trained palliative healthcare providers (11). Furthermore, SSA studies have documented that healthcare providers in PC are inadequately prepared to care for patients in pain (12). Several reasons for the lack of preparation have been identified, including absence of curriculum content related to pain management, and faculty attitudes and beliefs related to pain (13). One of the important factors influencing the successful delivery of PC is the healthcare providers' knowledge and experience, which determine not only their procedure but also their behaviour during the evaluation and treatment of patients $(11,14)$.

A major barrier to further development of PC in South Africa is the lack of data to inform service provision (15). PC research in South Africa has predominantly focused on opioid availability and the physical aspects of care, such as the assessment of pain and other symptoms, while neglecting the improvement of PC education for healthcare providers (16). Palliative medicine is of great relevance in the field of medical education through its emphasis on complex symptom controls, whole-patient care, an interdisciplinary team approach, enhanced communication skills and support programs for the bereaved (17).

A public health strategy, as recommended by the WHO, offers the best approach for translating knowledge and skills into evidence-based, cost-effective interventions that can reach everyone in need of PC in low-and-middle income countries (LMICs) (18). The WHO pioneered a public health strategy (PHS) for integrating PC into a country's health care system (18). The WHO PHS addresses 1) appropriate policies; 2) adequate drug availability; 3 ) education of policy makers, healthcare providers, and the public; and 4) implementation of PC services at all levels throughout the society (19). The education of healthcare providers has a great influence on their knowledge, which acts as a foundation for better clinical practice (20). Therefore, the purpose of this study was to determine healthcare providers' knowledge and perceived factors influencing cancer PC services in KZN.

\section{Methods}


This was a mixed methods study using structured questionnaires and FGDs for quantitative and qualitative aspects, respectively. The quantitative aspect was a cross-sectional study aimed at assessing healthcare providers' knowledge influencing the PC services in KZN. A total of 27 healthcare providers were recruited from January 2019 to March 2019 from the targeted facilities in KZN, namely: Inkosi Albert Luthuli Central Hospital, Addington Hospital, Grey's Hospital, Msunduzi Hospice and Chatsworth Hospice. This study included medical officers, radiologists, social workers, nurses, community caregivers (CCGs), a traditional healer and a spiritual healer offering PC services from each of the five healthcare facilities. Consistent with the literature, the qualitative component of this study used one FGD consisting of eight members to investigate the perceived factors influencing cancer PC services. An FGD was deemed effective for capturing information about social norms and the variety of opinions or views within a population (4).

\section{Recruitment and eligibility}

Quantitative component: All healthcare providers were selected through convenience sampling. For the purpose of this study, healthcare providers refer to medical officers, radiologists, social workers, nurses, CCGs, a traditional healer and a spiritual healer. Convenience sampling has been defined as accidental sampling or opportunity sampling. The researcher included those participants who were easy or convenient to approach (21). Participants were eligible if they were aged 18 and above and working as palliative healthcare providers in the oncology units, hospices and at a community level.

Qualitative component: Participants were recruited from the CCGs who attended the MLCCP palliative care training, held from $12^{\text {th }}-16^{\text {th }}$ November 2018. All participants were above the age of 18 years and involved in caring for patients with NCDs, especially cancer.

\section{Data collection}

Quantitative component: Data was collected through an interviewer-administered questionnaire, which took place at a private in-patient room to protect participants' privacy. The questionnaire was adapted from those presented in published work and took about 10-12 minutes to complete. None of the participants reported feeling discomfort or distress while the questionnaire was administered.

Qualitative component: An FGD was conducted in a separate room to protect the participants' privacy and to stimulate them to engage freely on the issues raised during the discussions. The FGD took about two hours to complete, but was enjoyable to the participants, as per their expressions at the end of the session.

\section{Data analysis}

Quantitative data analysis: Data was entered into REDcap (v.8.11.7) (21) and then exported to IBM SPSS Statistics (v.25) (22) for analysis. Data was further checked for possible errors and missing values. For descriptive analysis, socio-demographic data was summarized into tables. This included age, gender, 
marital status, level of education, employment status, geographical area, whether they had received PC training or not, years of working as a palliative healthcare provider and rating of care for PC patients.

Qualitative data analysis: NVIVO 12 Pro software (23) was used to analyze qualitative data. Thematic analysis was used to analyze the transcript of the FGD with CCGs, a traditional healer and a spiritual healer. Patterns were identified from the transcript of the healthcare providers' experiences of providing $P C$ services and their perceived factors influencing cancer PC services.

\section{Results}

\section{Participant characteristics}

A total of 27 participants took part in this study, the mean ( \pm SD) age was $42.52( \pm 11.37)$ years and $48.1 \%$ were within the age group $31-40$ years. The majority of participants were females $(77.7 \%)$ and $59.5 \%$ were married. More than four-fifths $(81.5 \%)$ had attended up to tertiary level as the highest level of education; $85.1 \%$ were permanently employed; and $96.3 \%$ were from urban areas. In terms of whether or not they had been trained in PC, the majority cited that they had received training (70.4\%), 55.5\% had less than five years' experience working as palliative healthcare providers and $51.8 \%$ rated their experience of caring for cancer patients as good (Table:1). 
Table 1

Socio-demographic characteristics of participants $(N=27)$

\begin{tabular}{|c|c|c|}
\hline Characteristics & Frequency & Percent \\
\hline \multicolumn{3}{|l|}{ Age (years) } \\
\hline $31-40$ & 13 & 48.1 \\
\hline $41-50$ & 9 & 33.3 \\
\hline$>50$ & 5 & 18.5 \\
\hline \multicolumn{3}{|c|}{ Mean age $( \pm S D): 42.52$ years $( \pm 11.37)$} \\
\hline \multicolumn{3}{|l|}{ Gender } \\
\hline Male & 6 & 22.2 \\
\hline Female & 21 & 77.7 \\
\hline \multicolumn{3}{|l|}{ Marital status } \\
\hline Unmarried & 8 & 29.6 \\
\hline Married & 16 & 59.5 \\
\hline Widowed & 3 & 11.1 \\
\hline \multicolumn{3}{|l|}{ Level of education } \\
\hline Secondary & 5 & 18.5 \\
\hline Tertiary/College & 22 & 81.5 \\
\hline \multicolumn{3}{|l|}{ Employment status } \\
\hline Permanently employed & 23 & 85.1 \\
\hline Temporarily employed & 4 & 14.8 \\
\hline \multicolumn{3}{|c|}{ Geographical Area of residence } \\
\hline Rural & 1 & 3.7 \\
\hline Urban & 26 & 96.3 \\
\hline \multicolumn{3}{|l|}{ Has training in $\mathrm{PC}$} \\
\hline Yes & 19 & 70.4 \\
\hline No & 8 & 29.6 \\
\hline \multicolumn{3}{|l|}{ Years working as a PHCP } \\
\hline$\leq 5$ years & 15 & 55.5 \\
\hline
\end{tabular}




\begin{tabular}{|lll|}
\hline Characteristics & Frequency & Percent \\
\hline$\geq 6$ years & 12 & 44.4 \\
\hline Rating of care for PC patients & & \\
\hline Fair & 13 & 48.1 \\
Good & 14 & 51.8 \\
\hline
\end{tabular}

\section{Quantitative Findings}

\section{Healthcare providers' knowledge about palliative care and years of experience working as a trained palliative healthcare provider}

An over-whelming majority of healthcare providers with working experience of 5-10 years rated their knowledge of $\mathrm{PC}$ as good compared to one third that rated it as fair. For those that had experience of 15 years or above, two-thirds rated themselves as having a good knowledge of PC and similarly, one third rated their knowledge as fair.

Conversely, less than half of those with 11-15 years' experience rated themselves as having good knowledge of PC and close to two-thirds rated themselves as possessing fair knowledge of PC. Among those who had less than five years' experience working as palliative healthcare providers, more than half rated their PC knowledge as fair. Less than half rated their knowledge as good. However, due to the small sample size, the level of significance was not tested. The researcher relied on their self-reported knowledge which was not further verified through an appropriate instrument (Fig: 3).

\section{Thematic analysis of the focus group discussion}

Analysis of the FGD transcripts elucidated the perceived barriers in patients seeking PC, culminating in three themes, namely: (1) effects of inter-departmental collaboration, (2) caregivers' perspectives regarding the complexities of PC seeking barriers among patients with cancer and (3) innate factors that sustain the CCGs' motivation. Further to the identified themes, participants were asked to list their expectations from the stakeholder. The FGD revealed that CCGs were passionate about caring for sick people. However, they had expectations from the Department of Health $(\mathrm{DoH})$ which, they felt, had not been met.

\section{Effects of departmental collaboration challenges on the community caregivers' performance}

This theme emerged from discussing the challenges faced by CCGs. It was also noted that these challenges negatively affected the CCGs' self-worth, in so far as caring for the sick is concerned. The nurses and other stakeholders of the DoH were particularly implicated in the infliction of a sense of worthlessness felt by CCGs. These stakeholders did not display a collaborative relationship with other stakeholders from the DoH. Challenges in the CCGs' performance included political issues (Participant C), 
lack of collaborative relationship among DoH stakeholders (Participant F) and feelings of worthlessness (Participant G).

"I know the sorrows of [the] Intshanga area when it comes to politics. When you are also in that area, you also experience problems with receiving help from the clinics because they say you are not on this side, on the other side there is a white person's centre nearby. You see, it's just.... They are involving us in things that have nothing to do with us, yet we are doing this for the community, and yet they also say the clinics are serving the community. And you get confused because no matter which side I fall under, am I not a member of the Intshanga area? That's the problem we have" (Participant $C$ ).

"I'm going to say this in the perspective of NGOs, the civil society and my experience with the DoH. We, we... we don't receive any support from the DoH, although we do sit in their meetings as, in their partners meetings in the district. Uhm, we have tried. We have MOUs with them. We... we go to the meetings, speak to the key people in terms of them assisting us, more especially with material and the availability of the CCGs. Because as much as we want to assist the community, we... we need to take services to them, but we don't have, we don't wear a cap of every profession. I can't be clinical to a patient that needs clinical help, so I need the Sisters from the DoH.

I can't be a social worker, I can't be a doctor all at the same time, a policeman, you know... But then, when you try and seek help from the DoH, if you are not going to give them anything that will benefit them, forget [it]!" (Participant F).

"Can you imagine going into a government facility and [you] feel so worthless and feel like you are nothing at all at that place? They don't notice you at all! You find that you have referred someone... They told you to refer people, then you do the referral, and you also accompany the person and then the nurses will say in front of the patient...'that person you are with is nothing here, don't think you are important just because you are with that person"' (Participant $G$ ).

\section{Caregivers' perspectives regarding the complexities of palliative care barriers among cancer patients}

This theme emerged from the identification of the perceived factors influencing PC among patients with cancer as shared by the caregivers. Barriers to PC among cancer patients included unemployment (Participant F), unfair treatment from the healthcare providers (Participant $G$ ) and stigma (Participant A).

"The biggest challenge that I face with my patients in terms of going to the clinic and getting their treatment per se, is unemployment. Uhm, because they have to spend almost the whole day at the clinic, just queuing for treatment, they miss a day at work. And when they come back, there is no work. The ones that are employed in the uhmm... What do they call it? Factories"(Participant F).

"Okay... what is also happening, just as Participant $F$ has said that they are dropping, collecting their pills or going for chemo because they stay at the clinic more than 4, 7, 5 hours. Some even prefer to go to Clairwood hospital because of the attitude they get from the other clinics. Once a person defaults or misses an appointment date for a short period, maybe you are supposed to go to the clinic on Tuesday, 
but you went on Thursday, they are going to scream at you. They will ask why you didn't come on the day, and they won't even want to listen to your explanation. People end up feeling like they are not happy in the clinics" (Participant G).

"They haven't got money to go to the clinic, so they won't go. They won't go, so they will become defaulters. Or 'my mother's sister is a nurse there. How can I go there? She will know I'm on ARVs and now I have cancer, then the whole family will know"' (Participant A).

\section{Innate factors that sustain the community caregiver motivation}

Despite the challenges which CCGs endure during the course of performing their duties, they reported some innate factors that kept them motivated to carry on. These innate factors are key drivers that keep the CCGs motivated and wanting to help more patients and families who are dealing with a lifethreatening illness. Innate factors included compassion (Participant E), spirituality (Participant D) and a supportive system (Participant B).

"Love and passion for caring for sick people - I think we are born with that thing. You have to love the sick person, don't just do it for money but do it because you want to, and you are willing to do that, and it's something that comes from within" (Participant E).

"Yeah, in my situation with the background of ministry, being in the church, preaching, I needed in life something that speaks to spirituality. What it means, you know the key result, as you would say... of, of... the core function of spirituality. The value is that when my master says, 'I was hungry, I was sick, and you didn't do this. Or whatever you did to the little one you did unto me.' For me, I needed a blend of the theory and practical. So, I felt staying in the church, I do a lot of routine [work] which is more theoretical preaching. But when you are looking in the... funny enough the departments were called ministries, Ministries of Health. You are putting the practical into what you are preaching to, to deal with poverty, disease, giving hope, as our logo says" (Participant D).

"I once had a serious case where I had a cancer patient who was 25 years old, so much that when she was experiencing difficulties, I was with her from stage 2 up until the end. When she reached a point where I could see that there was no longer any hope as everything had failed, because the doctors had failed, and everything else had failed, there is no way that she could still live, but I couldn't tell her. I told her that anytime you need to see me, you must just contact me. And her family, I sat down with her and her family and I asked to speak to them, even though she had already told them, and they were supportive. She had a three-year-old child who had no idea what was going on. He was just used to seeing his mother lying in bed all the time, and when I got there, I would remove her from the bed and take her to the lounge. I would tell her that she must go outside to get some fresh air, and not just be always sitting in the house. I told her she must get a wheelchair and go and sit outside and reminisce about her youth, back then when she was still herself and not sick. I would do that trying to press her, so that she could let go of what was troubling her so that she could be able to be active. She would be so happy, I 
would see that she would get so happy about being outside and then going back inside again. When the time would come for me to leave, you could see that she wouldn't be okay" (Participant B).

Further to the identified themes, participants were asked to list their expectations from the stakeholders, and these were the things they raised.

"My take was going to be maybe if we can form a collaboration with the DoH and other stakeholders. If they could understand very well that our main aim is to assist the sick members of the community, and that us as NGOS, we do have access to the community. Let them accept that and we [can] work in collaboration so that we can also have access to their health facilities... They are blocking you from using their laboratory, unless you are going to pay. Why do we have to pay for services that we are giving to people who are in need? You see. So, if they can accept that we are there to assist them... because we can get to the grassroots of the community, and they can't, it's a given fact! They can't leave their facilities and go to the community. But we can! ... We have resources to go to the community, so they must open their resources so that we can be able to help the community. At the end, it's all about the patient, that they must live" (Participant F).

\section{Discussion}

The discussion of the study highlighted striking findings such as the healthcare providers' good knowledge about PC, which is the key in ensuring that patients are well taken care of up to the end. Whilst views that $\mathrm{PC}$ giving is something that should come from within an individual and no amount of training can produce the best carer, participants appreciated their call to work as carers. They, however, pointed out that the effects of lack of departmental collaboration cripple them from delivering successful PC services.

Furthermore, participants pointed out perspectives regarding the complexities of PC seeking barriers among patients with cancer. Firstly, the study results demonstrated that healthcare providers have a good knowledge of PC. This is similar to findings of other studies on PC. For example, a study done by Gopal and Archana in 2016 documented that medical doctors in the oncology unit showed good PC knowledge (24). In addition, another study done by Khoshnazar et al., in 2016 showed that determinants of PC knowledge and good practice were possessing a minimum of a bachelor's degree and working in a tertiary health facility (25). However, participants whose undergraduate curriculum did not contain PC were found to demonstrate good practice when compared with others $(25,26)$. These results differ from the earlier studies conducted in SSA, where those who had training on PC both at undergraduate and formal in-service training demonstrated better practice of PC than those who had not been trained (27).

Secondly, participants expressed how they were affected by the departmental collaboration challenges and felt the need for a good relationship among the stakeholders, for the benefit of the patients. This was similar to the findings of the study conducted by Moetlo et al., (28) in Vhembe District, which found that the absence of a good alliance between healthcare providers from the DoH and CCGs is a wider problem within South Africa and should be urgently addressed in an effort to strengthen access to PC. 
Finally, this current study demonstrated the CCGs' perspectives regarding the complexities of PC seeking barriers among patients with cancer. Participants mentioned that patients were treated with disrespect by healthcare providers and this prevented them from actively seeking PC services. Previous studies have concluded that patients who have negative perceptions of the patient-provider relationship would be less likely to seek needed healthcare and that without such negative perceptions, reports of such feelings would be more prevalent among patients (29).

Furthermore, based on the previous studies, perceived discrimination even in the absence of socioeconomic disadvantages was associated with three-fold to nine-fold increased odds for refraining from seeking PC (30). The significant interaction effect of frequent discrimination and severe socio-economic disadvantage on refraining from seeking palliative care was more statistically consistent among women than men (31). This is also supported by a study conducted among Asian patients who reported underutilizing PC services because they held traditional beliefs about the illness and preferred to selfmanage cancer symptoms, a phenomenon common in the general population, worldwide (32).

\section{Study strengths and limitations}

A particularly strong aspect of this study was the use of mixed methods, which provided results that have a broader perspective of the overall issue or research problem. One of the important limitations was the fact that the assessment of healthcare providers' knowledge was based on self-reporting, rather than using standardized instruments. We are also unable to generalize the findings of the research because of its sampling technique which yielded a smaller than anticipated number of participants being recruited, with limited variables being included in the quantitative assessment. The views of healthcare personnel in clinics and hospitals were not included, as these healthcare providers were not part of the FGDs.

\section{Conclusion}

In conclusion, the findings of this study demonstrated that palliative healthcare providers have varying levels of competencies and that the perceived complexities of PC seeking barriers among patients with cancer are associated with low levels of PC seeking behaviour. Initiatives to support ongoing advocacy, education and training for healthcare providers are essential for improving awareness, skills and knowledge to deliver effective PC services.

\section{Declarations}

\section{Ethics approval and consent to participate}

The study was approved by the University of KwaZulu-Natal Biomedical Research Ethics Committee (REF: BE374/18) and Department of Health National Research Ethics Committee (KZ_201810_039). Ethics committees approved the written informed consent which was obtained from all the participants prior to participating in the study. 


\section{Consent for publication}

Not Applicable

\section{Availability of data and materials}

Data from this study is the property of the Province of KwaZulu-Natal, Department of Health and University of KwaZulu-Natal and cannot be made publicly available. All interested readers can access the dataset from DOH National Research Ethics Committee from the following contacts: Directorate, Health Research and Knowledge Management, physical address: 330 Langalibalele street, Pietermaritzburg, P/Bag X9051, Tel: +27 333952805 Fax: 0333943782 and UKZN-BREC from the following contacts: The Chairperson, Biomedical Research Ethics Administration Research Office, Westville Campus, Govan Mbeki Building University of KwaZulu-Natal P/Bag X54001, Durban, 4000 KwaZulu-Natal, South Africa Tel: +27 312604769 Fax: +27 312604609 Email: BREC@ukzn.ac.za.

\section{Competing interests}

The authors declare that they have no competing interests.

\section{Funding}

This work received support from Bristol-Myers Squibb Foundation [Grant number 1011]. The funder had no role in the study design, data collection and analysis, or decision to publish.

\section{Authors' contributions}

MSD designed the study, data collection, KWH carried out the analysis, and MSD drafted the manuscript. MSD analyzed data and KWH supervised writing up of manuscript; TGG \& KWH supervised the study and analysis, reviewed and modified the original manuscript. All authors have read and approved of the final version of the manuscript.

\section{Acknowledgements}

The research team wish to thank the KwaZulu-Natal cancer patients and healthcare providers in palliative care for their assistance with this project. We also thank all the health facilities in Durban and Pietermaritzburg, South Africa, especially Inkosi Albert Luthuli Central Hospital, Addington Hospital, Grey's Hospital, Msunduzi Hospice and Chatsworth Hospice. Additionally, the authors would like to thank the Discipline of Public Health Medicine and the University of KwaZulu-Natal (UKZN) as a whole for the provision of resources towards this study. This study forms the basis of a Master of Medical Science research report. MSD would like to express my sincere appreciation to the MLCCP team for their support and encouragement throughout the process. The research team is also thankful for the support from Bristol-Myers Squibb Foundation. 


\section{Abbreviations}

PC: Palliative care, LMICs: Low-middle-income countries, KZN: KwaZulu-Natal, SSA: sub-Saharan Africa, MLCCP: Multinational Lung Cancer Control Program, IALCH: Inkosi Albert Luthuli Central Hospital, CCG's: Community Caregivers, DoH: Department of Health, NCDs: Non-Communicable Diseases, WHO: World Health Organization.

\section{References}

1. Parkin DM, Sitas F, Chirenje M, Stein L, Abratt R, Wabinga H. Part I: Cancer in Indigenous Africansburden, distribution, and trends. The lancet oncology. 2008;9(7):683-92.

2. Harding R, Higginson IJ. Palliative care in sub-Saharan Africa. The Lancet. 2005;365(9475):1971-7.

3. Ddungu H. Palliative care: what approaches are suitable in developing countries? British journal of haematology. 2011;154(6):728-35.

4. Bohlius J, Valeri F, Maskew M, Prozesky H, Garone D, Sengayi M, et al. Kaposi's Sarcoma in HIVinfected patients in South Africa: Multicohort study in the antiretroviral therapy era. International journal of cancer. 2014;135(11):2644-52.

5. UNAIDS A. Epidemic Update 2007, Geneva, 2007.

6. Stewart B, Wild CP. World cancer report 2014. 2014.

7. Organization WH. World Health Organization definition of palliative care. World Health Organization Website Available online: who int/cancer/palliative/definition/en. 2014.

8. Saunders C. Hospice and palliative care. An interdisciplinary approach London: Edward Arnold. 1991.

9. Onyeka TC. Palliative care in Enugu, Nigeria: Challenges to a new practice. Indian journal of palliative care. 2011;17(2):131.

10. Selman L, Brighton L, Harding R. Palliative and supportive care needs of heart failure patients in Africa: a review of recent developments. Current opinion in supportive and palliative care. 2015;9(1):20-5.

11. Prem V, Karvannan H, Kumar SP, Karthikbabu S, Syed N, Sisodia V, et al. Study of nurses' knowledge about palliative care: a quantitative cross-sectional survey. Indian journal of palliative care. 2012;18(2):122.

12. Egan KA, Abbott P. Interdisciplinary team training: Preparing new employees for the specialty of hospice and palliative care. Journal of Hospice \& Palliative Nursing. 2002;4(3):161-71.

13. Goudge J, Gilson L, Russell S, Gumede T, Mills A. Affordability, availability and acceptability barriers to health care for the chronically ill: Iongitudinal case studies from South Africa. BMC health services research. 2009;9(1):75.

14. Sips I, Mazanderani AH, Schneider H, Greeff M, Barten F, Moshabela M. Community care workers, poor referral networks and consumption of personal resources in rural South Africa. PloS one. 2014;9(4):e95324. 
15. Iliyasu G, Dayyab FM, Habib ZG, Tiamiyu AB, Abubakar S, Mijinyawa MS, et al. Knowledge and practices of infection control among healthcare workers in a Tertiary Referral Center in North-Western Nigeria. Annals of African medicine. 2016;15(1):34.

16. Ayed A, Sayej S, Harazneh L, Fashafsheh I, Eqtait F. The Nurses' Knowledge and Attitudes towards the Palliative Care. Journal of Education and Practice. 2015;6(4):91-9.

17. Seely JF, Scott JF, Mount BM. The need for specialized training programs in palliative medicine. Cmaj. 1997;157(10):1395-7.

18. Group W. The World Health Organization quality of life assessment (WHOQOL): position paper from the World Health Organization. Social science \& medicine. 1995;41(10):1403-9.

19. Powell R, Downing J, Radbruch L, Mwangi-Powell F, Harding R. Advancing palliative care research in sub-Saharan Africa: from the Venice declaration, to Nairobi and beyond. Sage Publications Sage UK: London, England; 2008.

20. Saini S, Bhatnagar S. Cancer pain management in developing countries. Indian journal of palliative care. 2016;22(4):373.

21. Harris PA, Taylor R, Thielke R, Payne J, Gonzalez N, Conde JG. Research electronic data capture (REDCap) - a metadata-driven methodology and workflow process for providing translational research informatics support. Journal of biomedical informatics. 2009;42(2):377-81.

22. Gunzler $D$, Chen $T$, Wu $P$, Zhang $H$. Introduction to mediation analysis with structural equation modeling. Shanghai archives of psychiatry. 2013;25(6):390.

23. Edhlund B, McDougall A. Nvivo 12 Essentials: Lulu. com; 2019.

24. Gopal KS, Archana PS. Awareness, knowledge and attitude about palliative care, in general, population and health care professionals in tertiary care hospital. INTERNATIONAL JOURNAL OF SCIENTIFIC STUDY. 2016;3(10):31-5.

25. Khoshnazar TA, Rassouli M, Akbari ME, Lotfi-Kashani F, Momenzadeh S, Haghighat S, et al. Structural Challenges of Providing Palliative Care for Patients with Breast Cancer. Indian journal of palliative care. 2016;22(4):459-66.

26. Lentsoane PP, Meyer JC, Schellack N, Cameron DA. Challenges in the provision of palliative care at resource-limited South African hospice settings: palliative and chronic care. African Journal for Physical Health Education, Recreation and Dance. 2014;20(Supplement 1):420-32.

27. Ajisegiri WS, Abubakar AA, Gobir AA, Balogun MS, Sabitu K. Palliative care for people living with HIV/AIDS: Factors influencing healthcare workers' knowledge, attitude and practice in public health facilities, Abuja, Nigeria. BioRxiv. 2018:460709.

28. Moetlo GJ, Pengpid S, Peltzer K. An evaluation of the implementation of integrated community home-based care services in Vhembe District, South Africa. Indian journal of palliative care. 2011;17(2):137.

29. Blanchard J, Lurie N. RESPECT: Patient reports of disrespect in the healthcare setting and its impact on care. Journal of Family Practice. 2004;53(9):721-31. 
30. Wamala S, Merlo J, Boström G, Hogstedt C. Perceived discrimination, socioeconomic disadvantage and refraining from seeking medical treatment in Sweden. Journal of Epidemiology \& Community Health. 2007;61(5):409-15.

31. Chan CM, Wan Ahmad W, Md Yusof M, Ho G, Krupat E. Prevalence and characteristics associated with default of treatment and follow-up in patients with cancer. European journal of cancer care. 2015;24(6):938-44.

32. Zebrack BJ. Psychological, social, and behavioural issues for young adults with cancer. Cancer. 2011;117(S10):2289-94.

\section{Figures}

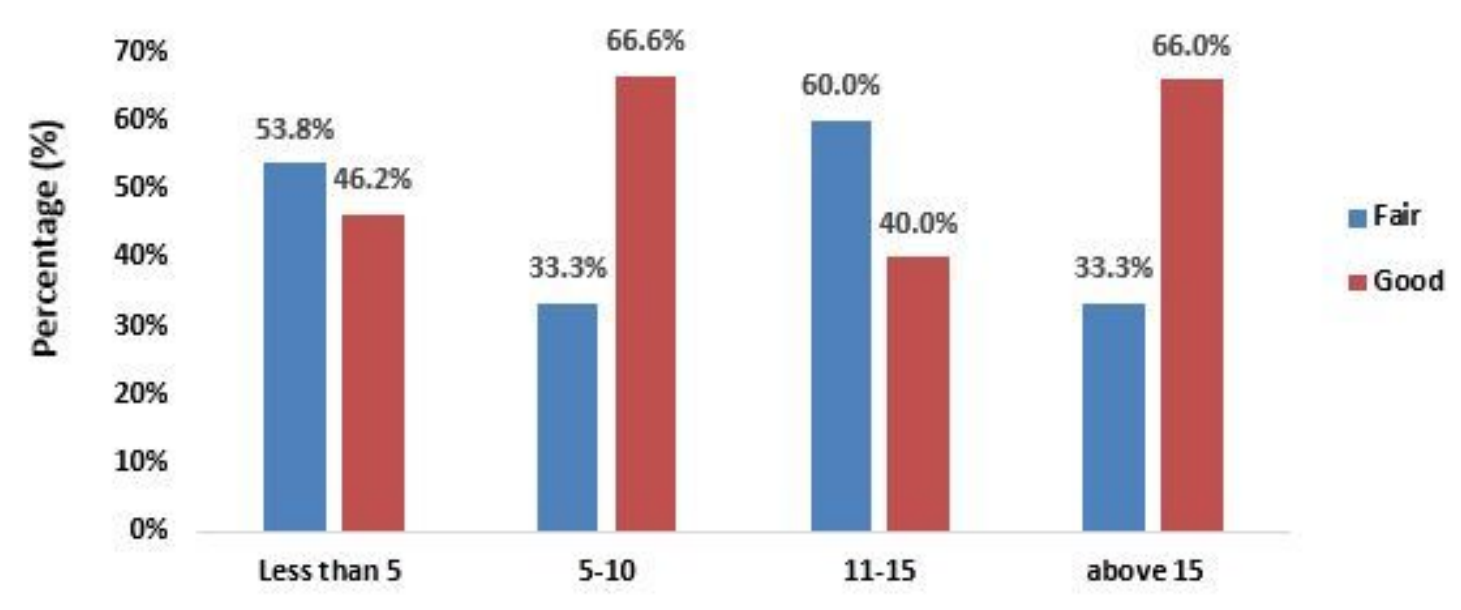

No. of years working as a healthcare provider in PC

\section{Figure 1}

Self-reported rating of palliative care knowledge among healthcare providers in KZN $(\mathrm{N}=27)$ 